\title{
Significance of Homocysteine Levels in the Management of Polycystic Ovarian Syndrome: A Literature Review
}

Varshitha Kondapaneni ${ }^{1}$, Sai Dheeraj Gutlapalli ${ }^{1}$, Sujan Poudel ${ }^{1}$, Mehwish Zeb ${ }^{1}$, Ijeoma A. Toulassi ${ }^{1}$, Ivan Cancarevic ${ }^{1}$

1. Internal Medicine, California Institute of Behavioral Neurosciences \& Psychology, Fairfield, USA

Corresponding author: Varshitha Kondapaneni, kondapanenivarshitha@gmail.com

\begin{abstract}
Polycystic ovarian syndrome (PCOS) is a complex disorder involving cardiovascular, metabolic, endocrine, and reproductive systems. Even though the exact etiology is not clear, many studies suggest genetic and environmental factors play a role. Homocysteine (Hcy) is considered to be an independent risk factor for atherogenic and thrombotic components of various systems. Many studies in the past have evaluated Hcy levels in the PCOS population. This article aims to elaborate on the importance of Hcy levels in the overall management of PCOS. We conducted a PubMed data search using combined keywords PCOS and homocysteine levels and manually screened relevant articles for the review while avoiding duplication of data. After the literature review, we analyzed the relationship between homocysteine levels and various components of PCOS. Most of the studies identified a statistically significant elevation in Hcy levels in PCOS women with insulin resistance, androgen excess, elevated markers of cardiovascular risk, recurrent pregnancy loss, and metformin treatment. We also examined studies that focused on treating hyperhomocysteinemia (Hhcy) in PCOS women. However, because of the limited sample sizes and various inclusion criteria used for subjects in the studies, their clinical implication is unclear in routine practice. Furthermore, we encourage clinicians to follow up on Hcy levels in PCOS women at high risk for any complications in their management course. We believe an observational study on a larger scale in a welldefined PCOS population would be useful to uncover the prevalence of elevated Hcy levels in PCOS women, which would help pave the way for establishing treatment guidelines on serum Hcy levels in PCOS management.
\end{abstract}

Received 10/01/2020 Review began $10 / 08 / 2020$ Review ended 10/23/2020 Published 10/23/2020

() Copyright 2020

Kondapaneni et al. This is an open access article distributed under the terms of the Creative Commons Attribution License CC-BY 4.0, which permits unrestricted use, distribution, and reproduction in any medium, provided the original author and source are credited.
Categories: Internal Medicine, Obstetrics/Gynecology Keywords: pcos, homocysteine levels

\section{Introduction And Background}

Polycystic ovarian syndrome (PCOS), also called Stein Leventhal Syndrome, is a complex, multifaceted disorder, with a global prevalence that varies from $2.2 \%$ to as high as $26 \%[1,2]$. As of 2010 , World Health Organization estimates show that it affected 116 million women worldwide (3.4\% of the population) [2]. Among women of reproductive age, PCOS is the most common endocrine disorder affecting metabolic and cardiovascular health apart from reproductive health $[3,4]$.

According to the 2003 revised Rotterdam criteria, PCOS is diagnosed when two out of the three following conditions are present after excluding other possible conditions that mimic PCOS phenotype: (1) clinical and/or biochemical signs of hyperandrogenism, (2) oligo- and/or anovulation, and (3) polycystic ovaries on ultrasound examination [5]. Although the exact etiology of PCOS is unknown, many studies strongly suggest genetic and environmental factors play a role in its causation [1,4]. Interestingly, recent studies identified a male PCOS equivalent syndrome in males related to women with PCOS. These males present with similar metabolic, clinical, and hormonal alterations as in PCOS women, which emphasizes a strong genetic component involved in the etiology of PCOS apart from lifestyle, ethnic origin, race, and other environmental factors $[4,6]$. PCOS and metabolic syndrome share common metabolic and cardiovascular complications, as insulin resistance is the potential pathogenetic mechanism for both [4]. Various metabolic, cardiovascular, clinical components of PCOS include obesity, impaired glucose tolerance, type 2 diabetes, hypertension, coronary vascular disease, obstructive sleep apnea, association with cancer, and dermatological manifestations of hyperandrogenemia [4].

Previous studies have demonstrated that compared with controls, serum homocysteine levels are significantly associated with insulin resistance and hyperinsulinemia in women with PCOS [7,8]. Homocysteine (Hcy) is a sulfur-containing amino acid present at the intersection of two pathways, remethylation and trans-sulphuration, which forms methionine and cysteine, respectively [3,9]. This amino acid metabolism requires vitamin B12, folate, and vitamin B6 as cofactors at different steps of the pathways [9]. Hyperhomocysteinemia (Hhcy) is documented to be an independent risk factor for atherosclerotic vascular disease and thromboembolic disorders [3,9]. Any defect in the enzymes involved in these pathways, deficiencies of vitamin cofactors, hyperinsulinemia, or drugs that cause Hhcy, can be responsible for long 
term cardiovascular complications or short-term reproductive outcomes in women with insulin-resistant PCOS [7,9-11]. Preliminary investigations done in PCOS women who were involved in various observational and randomized controlled trials demonstrated high serum homocysteine levels in most of the studies along with other cardiovascular disease serum biomarkers such as high sensitivity C-reactive protein, plasma soluble CD40 ligand (sCD40L), and asymmetric dimethylarginine (ADMA) [12,13]. As discussed above, homocysteine being an independent risk factor for cardiovascular disease and PCOS having long term cardiovascular complications, it is vital to know the association of elevated homocysteine levels in PCOS management.

In this literature review, we aimed to comprehensively discuss the overall association of Hhcy in managing PCOS patients. We discussed the effects of Hhcy on reproductive and cardiovascular components of PCOS, effects of the current treatment of PCOS on Hhcy, and suggested management of Hhcy in PCOS patients. For this, we collected relevant data from the PubMed database using the keywords homocysteine levels, PCOS. We manually screened and included relevant published articles from the PubMed database after using the MeSH strategy, regular keywords search, and combined keyword search (PCOS and Homocysteine levels) and avoided duplication of data.

\section{Review}

\section{Homocysteine levels and insulin resistance in PCOS}

Insulin resistance (IR) is the central pathogenetic feature in PCOS and is present in up to $70 \%$ of women with PCOS [4,14]. In several clinical situations, plasma insulin levels and increased Hcy levels are positively correlated [11]. It has been implicated that plasma insulin levels influence Hcy levels and its metabolism through effects on glomerular filtration or by inhibition of hepatic cystathione $\beta$ synthase activity $[11,14]$. Previous studies have evaluated the relationship between insulin resistance and Hcy levels in PCOS patients. In one such study, Schachter et al. found that Hcy levels were significantly elevated in IR PCOS patients $(12.4 \pm 8.4 \mu \mathrm{mol} / \mathrm{l})$ compared with non-IR PCOS patients $(9.6 \pm 4.4 \mu \mathrm{mol} / \mathrm{l})$, independent of the significant elevation of Hcy found in all infertile PCOS patients $(11.5 \pm 7.4 \mu \mathrm{mol} / \mathrm{l})(\mathrm{p}<0.001)$ [11]. A statistically significant correlation was identified between serum Hcy and insulin levels irrespective of BMI at the end of the study [11]. A similar study was done a decade later by Sachan Rekha et al. in infertile women with PCOS and without PCOS(controls), which showed statistically significant elevated levels of Hcy in PCOS and IR PCOS women when compared to controls $(\mathrm{p}<0.001)$ [14]. This study also concluded obesity is not an independent risk factor for elevated Hcy levels in PCOS women [14]. Bayraktar F et al. investigated a correlation between Hcy levels, IR, and androgen levels in women with PCOS and non-classic congenital adrenal hyperplasia (CAH) caused by 21-hydroxylase deficiency, as high androgen levels are a common characteristic for both disorders [15]. The study concluded the reason for Hhcy to be related to IR but not androgen levels [15]. A cross-sectional study done by Zhang et al. on 196 Chinese PCOS patients demonstrated that high levels of CD14++CD16+ inflammatory monocytes were associated with Hhcy and IR in PCOS patients [16]. Karadeniz et al. performed a genetic study on ABCA1 gene polymorphism in PCOS patients [17]. Compared with heterozygous and wild genotypes, this study discovered significantly higher levels of fasting insulin and Hcy levels in PCOS patients with the ABCA G1051A mutant genotype [17]. Also, a higher percentage of AA genotype and A allele of ABCA G2706A was found in PCOS patients when compared to controls [17].

In contrast, a study was done by Kilic-Okman et al. on 29 patients and 25 healthy subjects concluded that age, BMI, and IR were not related to levels of Hcy in PCOS patients [18]. They suggested serum Hcy increase independently in PCOS patients [18]. Overall, many studies proposed a significant association between Hcy levels and IR by observing at the cellular level, genetic level, and various other variables like androgen levels and BMI. However, the Kilic-Okman et al. study suggested no relation between Hcy and IR, which may be due to the study's small sample size. Furthermore, although a statistical significance was demonstrated in the studies by Schachter et al. and Sachan Rekha et al., the clinical relevance of these studies remains unclear as the total number of patients involved was low. Because of the limited sample sizes of the above studies and different criteria used to identify and include subjects for the studies, the results cannot be generalized in the PCOS population.

\section{Homocysteine levels and cardiovascular health in PCOS}

Hcy, with its primary atherogenic and prothrombotic properties, has a vital role in cardiovascular morbidity and mortality [3]. It exerts its effects through leucocyte recruitment, smooth cell proliferation, enhanced collagen production, foam cell formation, disrupting blood clotting mechanics, endothelial cell injury, and impairing nitric oxide production [3]. Studies have been done to evaluate the homocysteine levels in PCOS patients in the context of cardiovascular health. Yarali et al. performed a prospective case-control study on 30 PCOS patients and 30 healthy controls [19]. This study assessed systolic and diastolic function parameters along with Hcy levels and insulin sensitivity in both study groups, which yielded a trend of non-restrictive type diastolic dysfunction apart from elevated Hcy levels in PCOS women [19]. It concluded that cardiovascular disease risk in PCOS patients might be contributed by diastolic dysfunction discovered in this study, along with increased levels of Hcy in PCOS [19]. A study done by Battaglia C et al. to evaluate subclinical vascular risk in PCOS patients concluded that increased vascular risk is observed in PCOS [20]. It was done in 28 PCOS patients, 17 eumenorrheic polycystic ovaries (PCO) women, and 15 healthy controls, 
and demonstrated a significantly elevated uterine pulsatility index after doppler analysis apart from elevated Hcy and decreased plasma nitrate levels in PCOS patients [20]. Measurement of plasma soluble CD40 ligand(sCD40L) levels and Hcy levels in 31 patients with PCOS and 31 non-PCOS patients was done by Oktem et al. [13]. CD40 ligand, which belongs to the tumor necrosis family upon engagement with the CD40 receptor, promotes atherosclerosis, which is the leading cause of cardiovascular disease [13]. Results showed significantly higher levels of sCD40L and Hcy levels in PCOS patients when compared to controls $(\mathrm{p}<0.05)$ [13]. Mohamadin et al. studied plasma markers of cardiovascular disease in 50 Saudi women with PCOS and 40 controls without PCOS, emphasizing asymmetric dimethylarginine (ADMA) and Hcy levels [21]. A significantly elevated level of ADMA, which is a sensitive cardiovascular risk marker, as well as elevated Hcy level and lipid profile, were observed in the study $(\mathrm{p}<0.001)$ when compared with controls [21]. The study also concluded that clinicians should follow up on these markers to manage PCOS in reducing cardiovascular risk [21]. A study performed by Kaya et al. in 68 PCOS women and 68 healthy controls demonstrated an abnormal heart rate recovery (HRR) in PCOS patients who have elevated levels of Hcy and $C$ reactive protein [22]. A case-control study done by Lin et al. on 339 women, of which 84 women have Hhcy and 255 women having normal Hcy, identified a correlation between serum Hcy, serum total testosterone levels, and diastolic blood pressure [23]. Hhcy and hyperandrogenemia were shown to have a significant association after logistic regression analysis was performed (OR: 2.24, 95\% CI: 1.26-4.01) [23]. The association between Hhcy and biochemical hyperandrogenism may contribute to cardiovascular risk in women with PCOS [23].

Yarali et al. and Battaglia et al. identified diastolic dysfunction and vascular risk in PCOS women with Hhcy, respectively $[19,20]$. Still, because of the limited sample size, it is unclear about their clinical significance. A statistically significant elevation of cardiovascular risk markers like SCD40L, ADMA along with Hcy levels in the studies by Oktem et al. and Mohamadin et al. raises a question of whether to involve those markers in the routine clinical screening of PCOS to evaluate cardiovascular risk [13,21]. However, we suggest larger scale observational studies because of the large prevalence of PCOS in reproductive age women to understand the clinical significance of these markers in the routine management of PCOS. Abnormal HRR observed in the study by Kaya et al. is directly related to increased Hcy levels ( $<<0.001 ; 95 \%$ CI: 0.026-0.081) [22]. Furthermore, a statistical significance was identified between the Hhcy and hyperandrogenism association, which further increase concerns in the management of PCOS women's cardiovascular health [23].

\section{Homocysteine levels and reproductive health in PCOS}

Hhcy in PCOS women is implicated in increased pregnancy loss and reduced ovulation [24]. Hhcy, a risk factor for arterial and venous thrombosis, poses a threat to women with habitual abortion [25]. In PCOS patients undergoing assisted reproduction, the quality of oocytes, fertilization rate, and the quality of embryos are evaluated using concentrations of Hcy levels in follicular fluid [26]. Berker et al. did a study on 52 PCOS patients undergoing assisted reproduction [26]. A total of 94 follicular samples were analyzed, and after multiple linear regression analyses, follicular fluid Hcy level was shown to be an independent predictor of oocyte quality ( $<<0.001,95 \%$ CI: -0.25 to 0.09 ) and embryo quality ( $<<0.001,95 \%$ CI: -0.49 to 0.311 ) [26]. Also, follicular fluid Hcy is negatively correlated with fertilization rate $(\mathrm{r}=-0.85)$, follicular fluid vitamin B12 $(r=-0.44)$ and positively correlated with malonyl dialdehyde (MDA) $(r=0.51)[26]$. Chakraborty et al. performed a retrospective study on 126 PCOS women with recurrent pregnancy loss (RPL) and 117 nonPCOS women with matched age range as controls to evaluate Hhcy and IR's role in PCOS women with RPL [27]. A significantly higher rate of miscarriage was observed in PCOS women with Hhcy (70.63\%) when compared to PCOS women with normal Hcy levels $(29.36 \%)(\mathrm{p}<0.008)$ [27]. A prospective observational study performed by Chakraborty et al. in 336 women with RPL evaluated the difference between aspirin's efficacy versus combined aspirin-low molecular weight heparin (LMWH) in preventing RPL in Hhcy women [25]. The sole outcome measure was pregnancy salvage, which was $43.15 \%$ represented by women with normal Hcy, and much lower salvage rate in Hhcy women after aspirin therapy and $66.84 \%$ after combined aspirin-LMWH therapy [25]. After logistic regression analysis, it was determined that Hhcy was a significant predictor for pregnancy salvage rates in PCOS women [25]. The study concluded that in Hhcy women, combined aspirinLMWH therapy conferred added benefit in preventing RPL [25]. A study was done in JIPMER, Puducherry by Chitra et al. on 50 PCOS patients admitted for laparoscopic ovarian drilling (LOD) evaluated LOD's effects on serum Hcy levels and clinical pregnancy outcomes in PCOS women [28]. This study demonstrated a reduction in Hcy levels $(p<0.001)$ with a significant reduction in conceived groups $(p<0.001)$ when compared to non-conceived groups, improved clinical pregnancy(21/50), and ovulation rate (38/50) outcomes after LOD [28].

Based on Berker et al. study, increased follicular Hcy levels are a significant predictor of the oocyte, embryo quality, and fertilization rate in PCOS women undergoing assisted reproduction [26]. Two different studies done by Chakraborty P et al. proposed that higher miscarriage rates are seen in PCOS women with Hhcy, and combined aspirin-LMWH therapy benefitted Hhcy PCOS women in the prevention of RPL [25,27]. Therefore, we believe Hcy levels in serum and follicular fluid play a significant role in managing PCOS patients' reproductive health. Chitra et al. performed LOD, which yielded a considerable reduction in Hcy levels and improved clinical outcomes in PCOS women [28]. Because of this therapy's invasive nature and limited sample size in the study, it is not clear about its application on a larger scale. Based on the above studies' data, we believe investigating Hcy levels in managing PCOS patients' reproductive health plays a vital role in 


\section{Effects of PCOS treatment on homocysteine levels}

Some studies were done to evaluate the effects of PCOS treatment on serum Hcy levels. One such study done by Vrbíková et al. examined serum Hcy levels in PCOS patients treated with metformin [29]. Results showed significant elevation in Hcy levels (10.1 +/- 2.6 to $13.4+/-5.1$ micromol/l, $\mathrm{p}<0.05)$ after metformin treatment in nine PCOS women [29]. A randomized study was done by Kilicdag et al. in 30 PCOS patients randomized into two groups receiving two different treatments, metformin or rosiglitazone, and evaluated their effects on serum Hcy levels [30]. It demonstrated a significantly increased level of Hcy in both treatment groups (metformin- $\mathrm{p}=0.002$ and rosiglitazone- $\mathrm{p}=0.01$ ) [30]. The study concluded that treatment with insulin sensitizers could contribute to elevated Hcy levels in women with PCOS [30]. Palomba et al. performed a non-randomized double-blind placebo-controlled clinical study on 50 PCOS patients divided into two treatment groups with 25 PCOS patients treated with metformin +folic acid (experimental group) and other 25 patients on metformin+placebo(control group) for six months [10]. Significantly higher Hcy levels were observed in the control group than the experimental group $(\mathrm{p}<0.05)$ [10]. The researchers concluded that the addition of folic acid to metformin provided extra benefit to vascular endothelium [10]. An interventional study was performed by Esmaeilzadeh et al. on 18 PCOS patients treated with metformin for six months [31]. Assessment of serum Hcy levels, vitamin B12, folic acid levels after treatment with metformin demonstrated a significant decrease in vitamin B 12 levels ( $\mathrm{p}<0.002)$, and an increase in Hcy levels with statistically significant elevation observed in women with $\mathrm{BMI}>25 \mathrm{~kg} / \mathrm{m} 2(\mathrm{p}=0.01)$ when compared to before treatment [31]. Harmanci et al. determined that estradiol/drospirenone (EE-DRSP) plus spironolactone therapy for six months in PCOS women improve androgen excess in lean PCOS patients but increase the serum Hcy levels (13.1 \pm 5.2 vs. $17.6 \pm 5.3 \mu \mathrm{m}, \mathrm{p}<0.05)[32]$.

In contrast to the above studies, few studies suggested that Hcy levels are unaffected or decreased by metformin treatment or oral contraceptive treatment in PCOS patients. A study done by Riahinejad et al. demonstrated a significant reduction in Hcy levels $(\mathrm{p}<0.05)$ after treating with metformin for three months in 33 random PCOS patients [33]. Two prospective randomized placebo-controlled studies done by Carlsen et al. on 63 infertile PCOS women and 38 pregnant PCOS patients demonstrated no effect of metformin on Hcy levels both in non-pregnant and pregnant PCOS women [34]. Yilmaz et al. proposed no change in Hcy level after treating with metformin or rosiglitazone for three months in a sample size of 50 lean PCOS women divided into two groups for study along with 35 healthy subjects as controls [35]. Based on all the above data, the effects of PCOS treatment on serum Hcy levels appear controversial. Even though the above studies resulted in statistical significance regarding Hcy levels after specific treatment, it is unclear whether to evaluate serum Hcy levels in the management of all PCOS women undergoing treatment due to varying inclusion criteria of subjects used for the studies and limited study sample sizes. However, we believe it is essential to follow up on Hcy levels in high-risk PCOS patients undergoing treatment and report any observed abnormal differences in Hcy levels during or after therapy to build up data for future studies.

\section{Key studies that focused on the treatment of hyperhomocysteinemia in PCOS women}

Studies listed in Table 1 provide an overview of various treatment regimens investigated in the past in PCOS women, that significantly impact levels of Hcy after therapy for a specified time. This data provides clinicians with valuable information in treating Hhcy in PCOS women associated with insulin resistance, cardiovascular, metabolic, and reproductive health risk.

\begin{tabular}{|c|c|c|c|c|c|c|}
\hline No. & Author name & $\begin{array}{l}\text { Year of } \\
\text { publication }\end{array}$ & $\begin{array}{l}\text { Total sample } \\
\text { size }\end{array}$ & $\begin{array}{l}\text { Objective and type of } \\
\text { study }\end{array}$ & Results & $\begin{array}{l}\text { Conclusion of the } \\
\text { study }\end{array}$ \\
\hline 1. & $\begin{array}{l}\text { Randeva et al. } \\
{[36]}\end{array}$ & 2002 & $\begin{array}{l}21 \text { young } \\
\text { obese PCOS } \\
\text { women (12- } \\
\text { exercisers, 9- } \\
\text { nonexercisers) }\end{array}$ & $\begin{array}{l}\text { Effect of six-month } \\
\text { exercise program on } \\
\text { total plasma Hcy levels } \\
\text { in young overweight or } \\
\text { obese PCOS women }\end{array}$ & $\begin{array}{l}\text { They observed a statistically } \\
\text { significant decrease in plasma Hcy } \\
\text { levels }(p<0.001) \text { in the exercise group } \\
\text { compared to baseline. }\end{array}$ & $\begin{array}{l}\text { The study concluded } \\
\text { that regular exercise } \\
\text { lowers plasma Hcy } \\
\text { levels significantly in } \\
\text { young obese or } \\
\text { overweight PCOS } \\
\text { women }\end{array}$ \\
\hline 2. & $\begin{array}{l}\text { Kilicdag et al. } \\
\text { [37] }\end{array}$ & 2005 & $\begin{array}{l}\text { (60 PCOS } \\
\text { women) } \\
\text { Group 1-20 } \\
\text { Group 2-20 } \\
\text { Group 3-20 }\end{array}$ & $\begin{array}{l}\text { A randomized trial done } \\
\text { to assess the effects of } \\
\text { administration of B } \\
\text { group Vitamins and folic } \\
\text { acid on serum Hcy } \\
\text { levels in metformin } \\
\text { taking PCOS women. }\end{array}$ & $\begin{array}{l}21.17 \% \text { and } 8.33 \% \text { reduction in Hcy } \\
\text { levels were observed in women } \\
\text { supplemented with B group vitamins } \\
\text { or folic acid+ metformin, respectively. } \\
\text { A } 26.5 \% \text { increase in Hcy level was } \\
\text { observed in women taking only } \\
\text { metformin in three months. }\end{array}$ & $\begin{array}{l}\text { B group vitamins or } \\
\text { folic acid } \\
\text { supplementation } \\
\text { counteracted the } \\
\text { metformin's Hcy } \\
\text { elevation. }\end{array}$ \\
\hline & & & & A prospective study & & The study proposed \\
\hline
\end{tabular}




\section{Cureus}

\begin{tabular}{|c|c|c|c|c|c|c|}
\hline 3. & Gul et al. [38] & 2008 & $\begin{array}{l}30 \text { PCOS } \\
\text { women }\end{array}$ & $\begin{array}{l}\text { evaluated the effect of } \\
\text { oral contraceptive } \\
\text { ethinyl estradiol- } \\
\text { cyproterone acetate } \\
\text { (EE-CA) on serum Hcy } \\
\text { level in PCOS women. }\end{array}$ & $\begin{array}{l}\text { EE-CA therapy for three months } \\
\text { showed a statistically significant } \\
\text { reduction in Hcy levels }(p=0.01) \text {. }\end{array}$ & $\begin{array}{l}\text { that further studies are } \\
\text { required to know the } \\
\text { clinical benefit of this } \\
\text { (EE-CA) therapy even } \\
\text { though the decrease in } \\
\text { Hcy level was } \\
\text { statistically significant. }\end{array}$ \\
\hline 4. & $\begin{array}{l}\text { Kazerooni et } \\
\text { al. [39] }\end{array}$ & 2008 & $\begin{array}{l}70 \text { Hhcy } \\
\text { PCOS women } \\
\text { (32-IR, 38- } \\
\text { NIR) }\end{array}$ & $\begin{array}{l}\text { A prospective clinical } \\
\text { trial was done to } \\
\text { investigate folic acid's } \\
\text { effect in Hhcy PCOS } \\
\text { women with IR and NIR } \\
\text { after three-month } \\
\text { therapy. }\end{array}$ & $\begin{array}{l}\text { After treatment, serum Hcy levels } \\
\text { were significantly decreased in both } \\
\text { groups. ( } p<0.001-\mathrm{IR}, p<0.001-\mathrm{NIR})\end{array}$ & $\begin{array}{l}\text { It was concluded that } \\
\text { after folic acid therapy } \\
\text { for three months, } \\
\text { serum Hcy levels in } \\
\text { Hhcy PCOS women } \\
\text { significantly reduced } \\
\text { with more reduction in } \\
\text { NIR PCOS women. }\end{array}$ \\
\hline 5. & $\begin{array}{l}\text { Kaya et al. } \\
\text { [40] }\end{array}$ & 2009 & $\begin{array}{l}52 \text { PCOS } \\
\text { women Group } \\
1-26 \text { Group 2- } \\
2652 \text { controls } \\
\text { (age \& BMI } \\
\text { matched) }\end{array}$ & $\begin{array}{l}\text { A prospective } \\
\text { randomized study } \\
\text { performed to test the } \\
\text { hypothesis Hhcy in } \\
\text { PCOS women improved } \\
\text { with statins. }\end{array}$ & $\begin{array}{l}\text { Twelve weeks of treatment with } \\
\text { atorvastatin (group } 1 \text { ) \& simvastatin } \\
\text { (group 2) significantly decreased Hcy } \\
\text { levels( }(p<0.01 \text { ) in PCOS women with } \\
\text { more decrease observed in the } \\
\text { atorvastatin group. }\end{array}$ & $\begin{array}{l}\text { The study proposed } \\
\text { that statin therapy } \\
\text { helps in the reduction } \\
\text { of serum Hcy levels in } \\
\text { PCOS women. }\end{array}$ \\
\hline 6. & $\begin{array}{l}\text { Makedos et } \\
\text { al. [41] }\end{array}$ & 2010 & $\begin{array}{l}83 \text { PCOS } \\
\text { women } \\
\text { (divided into } \\
\text { five groups for } \\
\text { five different } \\
\text { regimes) }\end{array}$ & $\begin{array}{l}\text { A prospective matched } \\
\text { study done to assess } \\
\text { the effects of five } \\
\text { different hormonal } \\
\text { regimes on serum Hcy } \\
\text { and serum hsCRP } \\
\text { levels in PCOS women. }\end{array}$ & $\begin{array}{l}\text { All five treatment regimens } 1 . \\
\text { Conjugated estrogens+ cyproterone } \\
\text { acetate, } 2.17 \beta \text {-estradiol + } \\
\text { cyproterone acetate, } 3 \text {. Ethinyl } \\
\text { estradiol+ cyproterone acetate (high } \\
\text { dose), } 4 \text {. Ethinyl estradiol+ } \\
\text { cyproterone acetate (low dose), } 5 . \\
\text { Ethinyl estradiol+ desogetrel, } \\
\text { demonstrated significant reduction of } \\
\text { Hcy levels( }(p<0.001 \text { ) when measured } \\
\text { after four, seven, } 12 \text { months }\end{array}$ & $\begin{array}{l}\text { Even though all five } \\
\text { regimens favored the } \\
\text { reduction of Hcy levels, } \\
\text { it concluded that 17ß- } \\
\text { estradiol + cyproterone } \\
\text { acetate regime had the } \\
\text { most favorable effect in } \\
\text { PcOS women in terms } \\
\text { of both Hcy and hsCRP } \\
\text { levels reduction. }\end{array}$ \\
\hline 7. & $\begin{array}{l}\text { Bahmani et al. } \\
\text { [42] }\end{array}$ & 2014 & $\begin{array}{l}69 \text { PCOS } \\
\text { women (18-40 } \\
\text { years age) } \\
\text { (Divided into } \\
\text { three equal } \\
\text { groups) Group } \\
1 \text { - folate } 1 \\
\mathrm{mg} / \text { day Group } \\
\text { 2- folate } 5 \\
\mathrm{mg} / \text { day, } \\
\text { Group 3- } \\
\text { placebo }\end{array}$ & $\begin{array}{l}\text { A randomized, double- } \\
\text { blinded placebo- } \\
\text { controlled clinical trial } \\
\text { conducted to assess } \\
\text { the effects of folate } \\
\text { therapy for eight weeks } \\
\text { on inflammatory factors } \\
\text { and biomarkers of } \\
\text { oxidative stress in } \\
\text { PCOS women. }\end{array}$ & $\begin{array}{l}\text { The study resulted in a statistically } \\
\text { significant decrease in Hcy levels in } \\
\text { women treated with } 5 \mathrm{mg} / \text { day folate } \\
(p<0.05) \text { compared with other } \\
\text { treatment groups. }\end{array}$ & $\begin{array}{l}\text { Therefore, } 5 \mathrm{mg} / \mathrm{day} \\
\text { folate Supplementation } \\
\text { had favorable effects } \\
\text { on inflammatory and } \\
\text { oxidative stress } \\
\text { biomarkers in PCOS } \\
\text { women. }\end{array}$ \\
\hline 8. & $\begin{array}{l}\text { Salehpour et } \\
\text { al. [43] }\end{array}$ & 2016 & $\begin{array}{l}50 \text { PCOS } \\
\text { women }\end{array}$ & $\begin{array}{l}\text { This pilot study was } \\
\text { done to evaluate the } \\
\text { effects of myoinositol } \\
\text { (MI) on the } \\
\text { cardiovascular and } \\
\text { metabolic profile of } \\
\text { PCOS women over } 30 \\
\text { years of age. }\end{array}$ & $\begin{array}{l}\text { After three months of therapy with Ml } \\
2 \mathrm{~g}+200 \mu \mathrm{g} \text { of folic acid, a } \\
\text { statistically significant reduction of } \\
\text { serum Hcy levels( } \mathrm{p}<0.008) \text { was } \\
\text { observed along with significant } \\
\text { improvement in other metabolic and } \\
\text { cardiovascular parameters of PCOS } \\
\text { women. }\end{array}$ & $\begin{array}{l}\text { Even though a } \\
\text { statistically significant } \\
\text { reduction in Hcy levels } \\
\text { and improved other } \\
\text { parameters were } \\
\text { observed after } \\
\text { treatment with Ml+ folic } \\
\text { acid, they suggested } \\
\text { further studies on a } \\
\text { larger population to } \\
\text { apply therapy clinically. }\end{array}$ \\
\hline 9. & $\begin{array}{l}\text { Stracquadanio } \\
\text { et al. [44] }\end{array}$ & 2018 & $\begin{array}{l}100 \text { PCOS } \\
\text { women }\end{array}$ & $\begin{array}{l}\text { The study aimed to } \\
\text { compare clinical, } \\
\text { metabolic, endocrine } \\
\text { parameters in two } \\
\text { treatment groups of } \\
\text { PCOS women after six } \\
\text { months of continuous }\end{array}$ & $\begin{array}{l}\text { Metabolic assessment in the results } \\
\text { showed a significant decrease in Hcy } \\
\text { levels and total cholesterol levels in }\end{array}$ & $\begin{array}{l}\text { Study concluded that } \\
\text { the combination } \\
\text { therapy (Ml+ gymnemic } \\
\text { acid }+\mathrm{L} \text { methyl folate) } \\
\text { could be a good option }\end{array}$ \\
\hline
\end{tabular}




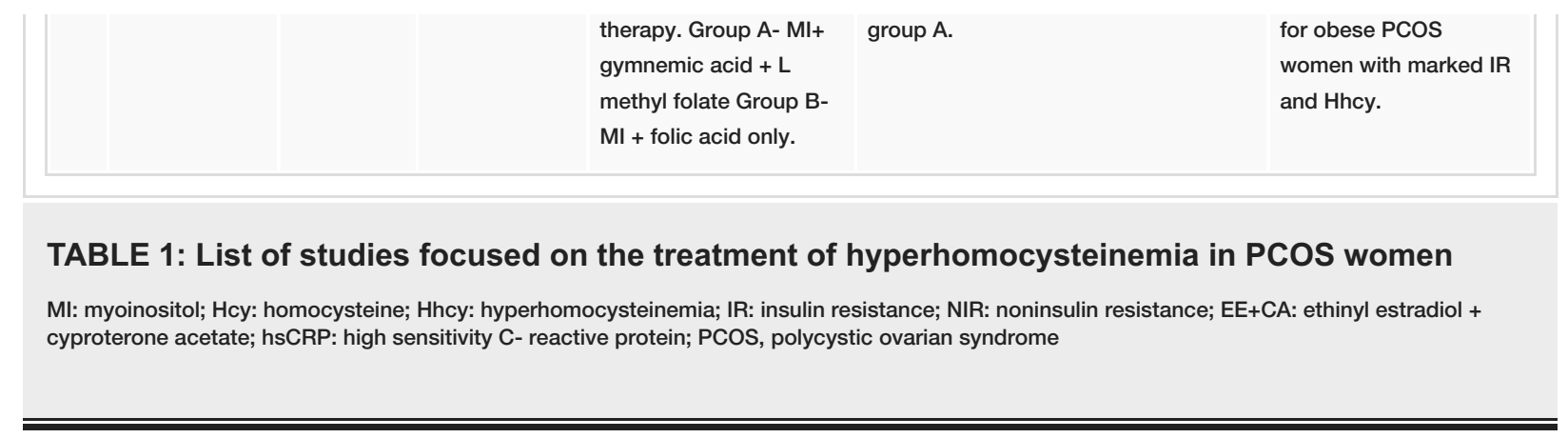

A statistically significant reduction in Hcy levels was observed in PCOS women doing regular exercise or therapy with B group vitamins, folic acid (5 mg/day), or statins therapy (especially atorvastatin) or EE+CA (ethinyl estradiol + cyproterone acetate) therapy or MI (myoinositol) + folic acid therapy for a specified amount of time. A recent study done in 2018 by Stracquadanio et al. investigated a combination therapy of MI + gymnemic acid + L methyl folate in PCOS women with IR and Hhcy [44]. It is postulated that Gymnemic acid, with its anti-diabetic properties, anti-inflammatory, and delay glucose absorption from blood, has a synergistic action to myoinositol's insulin-mimetic properties [44]. Also, in contrast to folic acid, L methyl folate has higher bioavailability, absorption rate, and no drug/food interactions [44]. As the study was done in 100 PCOS women, given the higher prevalence rates of PCOS, we suggest a randomized clinical trial on a larger scale to know the clinical implication of this combination therapy.

\section{Conclusions}

Homocysteine being an independent risk factor for atherogenic and thrombotic components of various systems and many past studies identifying an association between PCOS and Hcy, we aimed through this article to review the overall importance of Hcy levels in association with various components of PCOS. IR PCOS women demonstrated higher Hcy levels when compared to NIR PCOS women in multiple studies. We believe excess serum Hcy levels add extra risk to PCOS women's cardiovascular health as studies identified diastolic dysfunction, increased vascular risk, Hcy levels associated with excess androgen, and elevated Hcy levels along with other cardiovascular risk markers in PCOS women. Use of aspirin-LMWH combination improved RPL in Hhcy PCOS women, and levels of Hcy are used as a predictor for oocyte, embryo quality, and fertilization rates in assisted reproduction of PCOS women. It is possible that commonly used PCOS treatment regimens like metformin can affect serum Hcy levels. These findings concern the role of Hcy levels in managing PCOS women and raise a question if the broader application of investigating Hcy levels and treating the Hhcy in PCOS women favors the course of PCOS management in the long run. We recommend an observational study on a larger scale to know the prevalence of elevated Hcy levels in a welldefined larger PCOS population in order to include it in routine clinical practice.

\section{Additional Information \\ Disclosures}

Conflicts of interest: In compliance with the ICMJE uniform disclosure form, all authors declare the following: Payment/services info: All authors have declared that no financial support was received from any organization for the submitted work. Financial relationships: All authors have declared that they have no financial relationships at present or within the previous three years with any organizations that might have an interest in the submitted work. Other relationships: All authors have declared that there are no other relationships or activities that could appear to have influenced the submitted work.

\section{References}

1. Vidya Bharathi R, Swetha S, Neerajaa J, et al.: An epidemiological survey: effect of predisposing factors for PCOS in Indian urban and rural population. Middle East Fertil Soc J. December, 22:313-316. 10.1016/j.mefs.2017.05.007

2. Kabel AM: Polycystic ovarian syndrome: Insights into pathogenesis, diagnosis, prognosis, pharmacological and non-pharmacological treatment. Pharmaceutical Bioprocess. 2016, 4:7-12.

3. Salehpour S, Manzor-Al-Ajdad O, Samani EN, Abadi A: Evaluation of homocysteine levels in patients with polycystic ovarian syndrome. Int J Fertil Steril. 2011 Jan, 4:168-171.

4. Ehrmann DA: Polycystic ovary syndrome. N Engl J Med. 2005, 352:1223-1236. 10.1056/NEJMra041536

5. The Rotterdam ESHRE/ASRM-sponsored PCOS consensus workshop group: Revised 2003 consensus on diagnostic criteria and long-term health risks related to polycystic ovary syndrome. Hum Reprod. 2004, 19:41-47. 10.1093/humrep/deh098

6. Di Guardo F, Cerana MC, D'urso G, Genovese F, Palumbo M: Male PCOS equivalent and nutritional restriction: are we stepping forward?. Med Hypotheses. 2019, 126:1-3. 10.1016/j.mehy.2019.03.003

7. Diwaker A, Kishore D: Evaluation of plasma homocysteine levels in patients of PCOS . J Assoc Physicians India. 2018, 66:17-20.

8. Badawy A, State O, El Gawad SSA, El Aziz OA: Plasma homocysteine and polycystic ovary syndrome: the missed link. Eur J Obstet Gynecol Reprod Biol. 2007, 131:68-72. 10.1016/j.ejogrb.2006.10.015 
9. Kumar A, Palfrey HA, Pathak R, et al.: The metabolism and significance of homocysteine in nutrition and health. Nutr Metab. 2017, 14:78. 10.1186/s12986-017-0233-z

10. Palomba S, Falbo A, Giallauria F, et al.: Effects of metformin with or without supplementation with folate on homocysteine levels and vascular endothelium of women with polycystic ovary syndrome. Diab Care. 2010, 33:246-251. 10.2337/dc09-1516

11. Schachter M, Raziel A, Friedler S, Strassburger D, Bern O, Ron-El R: Insulin resistance in patients with polycystic ovary syndrome is associated with elevated plasma homocysteine. Hum Reprod. 2003, 18:721727. 10.1093/humrep/deg190

12. Elci E, Kaya C, Cim N, Yildizhan R, Elci GG: Evaluation of cardiac risk marker levels in obese and non-obese patients with polycystic ovaries. Gynecol Endocrinol. 2017, 33:43-47. 10.1080/09513590.2016.1203893

13. Oktem M, Ozcimen EE, Uckuyu A, et al.: Polycystic ovary syndrome is associated with elevated plasma soluble CD40 ligand, a marker of coronary artery disease. Fertil Steril. 2009, 91:2545-2550. 10.1016/j.fertnstert.2008.03.039

14. Rekha S, Patel ML, Pooja G, et al.: Correlation between elevated homocysteine levels and insulin resistance in infertile women with or without polycystic ovary syndrome in North Indian population. Int J Med Medical Sci. 2013, 5:116-123. 10.5897/IJMMS12.069

15. Bayraktar F, Dereli D, Ozgen AG, Yilmaz C: Plasma homocysteine levels in polycystic ovary syndrome and congenital adrenal hyperplasia. Endocr J. 2004, 51:601-608. 10.1507/endocrj.51.601

16. Zhang B, Qi X, Zhao Y, et al.: Elevated CD14++CD16+ monocytes in hyperhomocysteinemia-associated insulin resistance in polycystic ovary syndrome. Reprod Sci. 2018, 25:1629-1636. 10.1177/1933719118756772

17. Karadeniz M, Erdoğan M, Ayhan Z, et al.: Effect Of G2706A and G1051A polymorphisms of the ABCA1 gene on the lipid, oxidative stress and homocystein levels in Turkish patients with polycystıc ovary syndrome. Lipids Health Dis. 2011, 10:193. 10.1186/1476-511X-10-193

18. Kilic-Okman T, Guldiken S, Kucuk M: Relationship between homocysteine and insulin resistance in women with polycystic ovary syndrome. Endocr J. 2004, 51:505-508. 10.1507/endocrj.51.505

19. Yarali H, Yildirir A, Aybar F, et al.: Diastolic dysfunction and increased serum homocysteine concentrations may contribute to increased cardiovascular risk in patients with polycystic ovary syndrome. Fertil Steril. 2001, 76:511-516. 10.1016/s0015-0282(01)01937-9

20. Battaglia C, Mancini F, Cianciosi A, et al.: Vascular risk in young women with polycystic ovary and polycystic ovary syndrome. Obstet Gynecol. 2008, 111:385-395. 10.1097/01.AOG.0000296657.41236.10

21. Mohamadin AM, Habib FA, Al-Saggaf AA: Cardiovascular disease markers in women with polycystic ovary syndrome with emphasis on asymmetric dimethylarginine and homocysteine. Ann Saudi Med. 2010, 30:278283. 10.4103/0256-4947.65255

22. Kaya C, Akgül E, Pabuccu R: C-reactive protein and homocysteine levels are associated with abnormal heart rate recovery in women with polycystic ovary syndrome. Fertil Steril. 2010, 94:230-235. 10.1016/j.fertnstert.2009.02.076

23. Lin YH, Huang SY, Hsu MI, et al.: Hyperhomocysteinaemia is associated with biochemical hyperandrogenaemia in women with reproductive age. Eur J Obstet Gynecol Reprod Biol. 2013, 171:314-318. 10.1016/j.ejogrb.2013.09.041

24. Chang H, Xie L, Ge H, et al.: Effects of hyperhomocysteinaemia and metabolic syndrome on reproduction in women with polycystic ovary syndrome: a secondary analysis. Reprod Biomed Online. 2019, 38:990-998. 10.1016/j.rbmo.2018.12.046

25. Chakraborty P, Banerjee S, Saha P, et al.: Aspirin and low-molecular weight heparin combination therapy effectively prevents recurrent miscarriage in hyperhomocysteinemic women. PLoS One. 2013, 8:e74155. 10.1371/journal.pone.0074155

26. Berker B, Kaya C, Aytac R, Satiroglu H: Homocysteine concentrations in follicular fluid are associated with poor oocyte and embryo qualities in polycystic ovary syndrome patients undergoing assisted reproduction. Hum Reprod. 2009, 24:2293-2302. 10.1093/humrep/dep069

27. Chakraborty P, Goswami SK, Rajani S, et al.: Recurrent pregnancy loss in polycystic ovary syndrome: role of hyperhomocysteinemia and insulin resistance. PLoS One. 2013, 8:e64446. 10.1371/journal.pone.0064446

28. Chitra T, Papa D, Sinha P, Nandeesha H: Laparoscopic ovarian drilling reduces serum homocysteine levels in women with polycystic ovary syndrome. Eur J Obstet Gynecol Reprod Biol. 2018, 221:135-138. 10.1016/j.ejogrb.2017.12.048

29. Vrbíková J, Bicíková M, Tallová J, Hill M, Stárka L: Homocysteine and steroids levels in metformin treated women with polycystic ovary syndrome. Exp Clin Endocrinol Diab. 2002, 110:74-76. 10.1055/s-2002-23489

30. Kilicdag EB, Bagis T, Zeyneloglu HB, et al.: Homocysteine levels in women with polycystic ovary syndrome treated with metformin versus rosiglitazone: a randomized study. Hum Reprod. 2005, 20:894-899. 10.1093/humrep/deh700

31. Esmaeilzadeh S, Gholinezhad-Chari M, Ghadimi R: The effect of metformin treatment on the serum levels of homocysteine, folic acid, and vitamin b12 in patients with polycystic ovary syndrome. J Hum Reprod Sci. 2017, 10:95-101. 10.4103/jhrs.JHRS_74_16

32. Harmanci A, Cinar N, Bayraktar M, Yildiz BO: Oral contraceptive plus antiandrogen therapy and cardiometabolic risk in polycystic ovary syndrome. Clin Endocrinol. 2013, 78:120-125. 10.1111/j.13652265.2012.04466.x

33. Riahinejad S, Mirdamadi A, Alizadeh E: Effects of metformin treatment on homocysteine levels and metabolic parameters of women with polycystic ovary syndrome. J Family Reprod Health. 2015, 9:172-176.

34. Carlsen SM, Kjøtrød S, Vanky E, Romundstad P: Homocysteine levels are unaffected by metformin treatment in both nonpregnant and pregnant women with polycystic ovary syndrome. Acta Obstet Gynecol Scand. 2007, 86:145-150. 10.1080/00016340600855946

35. Yilmaz M, Bukan N, Ayvaz G, et al.: The effects of rosiglitazone and metformin on oxidative stress and homocysteine levels in lean patients with polycystic ovary syndrome. Hum Reprod. 2005, 20:3333-3340. 10.1093/humrep/dei258

36. Randeva HS, Lewandowski KC, Drzewoski J, et al.: Exercise decreases plasma total homocysteine in 
overweight young women with polycystic ovary syndrome. J Clin Endocrinol Metab. 2002, 87:4496-4501. 10.1210/jc.2001-012056

37. Kilicdag EB, Bagis T, Tarim E, et al.: Administration of B-group vitamins reduces circulating homocysteine in polycystic ovarian syndrome patients treated with metformin: a randomized trial. Hum Reprod. 2005, 20:1521-1528. 10.1093/humrep/deh825

38. Gul OB, Somunkiran A, Yucel O, Demirci F, Ozdemir I: The effect of ethinyl estradiol-cyproterone acetate treatment on homocysteine levels in women with polycystic ovary syndrome. Arch Gynecol Obstet. 2008, 277:25-30. 10.1007/s00404-007-0401-x

39. Kazerooni T, Asadi N, Dehbashi S, Zolghadri J: Effect of folic acid in women with and without insulin resistance who have hyperhomocysteinemic polycystic ovary syndrome. Int J Gynaecol Obstet. 2008, 101:156-160. 10.1016/j.ijgo.2007.10.024

40. Kaya C, Cengiz SD, Berker B, Demirtaş S, Cesur M, Erdoğan G: Comparative effects of atorvastatin and simvastatin on the plasma total homocysteine levels in women with polycystic ovary syndrome: a prospective randomized study. Fertil Steril. 2009, 92:635-642. 10.1016/j.fertnstert.2008.06.006

41. Makedos A, Goulis DG, Papanikolaou A, Panidis D: Serum high-sensitivity C-reactive protein and homocysteine changes during hormonal therapy in women with polycystic ovary syndrome: a prospective, matched study. Angiology. 2010, 61:595-601. 10.1177/0003319709361198

42. Bahmani F, Karamali M, Shakeri H, Asemi Z: The effects of folate supplementation on inflammatory factors and biomarkers of oxidative stress in overweight and obese women with polycystic ovary syndrome: a randomized, double-blind, placebo-controlled clinical trial. Clin Endocrinol. 2014, 81:582-587. 10.1111/cen.12451

43. Salehpour S, Nazari L, Hoseini S, Saharkhiz N, Ghazi F, Sohrabi MR: A potential therapeutic role of myoinositol in the metabolic and cardiovascular profile of PCOS Iranian women aged between 30 and 40 years. Int J Endocrinol. 2016, 2016:7493147. 10.1155/2016/7493147

44. Stracquadanio M, Ciotta L, Palumbo MA: Effects of myo-inositol, gymnemic acid, and L-methylfolate in polycystic ovary syndrome patients. Gynecol Endocrinol. 2018, 34:495-501. 10.1080/09513590.2017.1418852 